\title{
TEKNOLOGI SAMBUNG MINI UNTUK MENDAPATKAN BIBIT TANAMAN DURIAN UNGGUL BAGI MASYARAKAT PEKEBUN DURIAN DI BATU BUSUK
}

\author{
Shalati Febjislami ${ }^{* *}$, P.K. Dewi Hayati ${ }^{* *}$, Sutoyo ${ }^{1}$ dan Panca Jarot Santoso ${ }^{2}$ \\ ${ }^{1}$ Program Studi Agroteknologi Fakultas Pertanian Universitas Andalas \\ ${ }^{2}$ Balai Penelitian Tanaman Buah (Balitbu) Tropika, Solok \\ *)Email: pkdewihayati@agr.unand.ac.id
}

\begin{abstract}
ABSTRAK
Kampung Batu Busuk, kelurahan Lambung Bukit, Kecamatan Pauh, Kota Padang merupakan salah satu daerah penghasil durian unggul. Namun durian yang ada saat ini merupakan durian alam yang dibudidayakan dengan pemeliharaan yang minim. Tanaman durian juga sudah tua sehingga kurang produktif dan berasal dari perbanyakan biji sehingga kualitas produk tidak seragam. Dengan demikian dibutuhkan transfer teknologi tepat guna yang dapat menyediakan bibit dalam waktu singkat dan cepat, mudah diimplementasikan dengan tingkat keberhasilan yang tinggi. Teknologi sambung mini diharapkan menjadi solusi permasalahan pertanaman durian di Batu Busuk. Kegiatan pendampingan pekebun durian telah dimulai dari tahun 2018 dan berlanjut hingga sekarang. Pembibitan durian dilakukan dari bulan Juli 2019 dan penyerahan bibit kepada masyarakat dilakukan pada Februari 2020. Penyuluhan, demonstrasi plot dan pelatihan digunakan sebagai metode kegiatan transfer teknologi sambung mini kepada masyarakat pekebun durian. Berdasarkan kegiatan yang telah dilakukan, dapat disimpulkan bahwa permasalahan penyediaan bibit untuk peremajaan tanaman durian di Batu Busuk dapat diatasi dengan penyediaan bibit durian sambung mini. Pembibitan durian dengan teknologi sambung mini berhasil dilakukan dan mendapatkan kurang lebih 1100 bibit. Tingkat keberhasilan sambung mini yang dilakukan oleh pekebun durian baru mencapai $43 \%$, mengindikasikan keterampilan berperan penting terhadap tingkat keberhasilan sambung. Hasil evaluasi terhadap pertumbuhan bibit menunjukkan bahwa pekebun durian sebaiknya menggunakan benih berukuran sedang dan besar sebagai sumber bibit untuk batang bawah karena memberikan pertumbuhan yang lebih baik. Teknologi sambung mini pada kegiatan pembibitan durian perlu terus dilakukan secara mandiri dan berkelanjutan dengan menggunakan entres yang berasal dari durian unggul lokal Batu Busuk sendiri dalam rangka pengembangan durian Batu Busuk.
\end{abstract}

Kata Kunci: Kampung Batu Busuk, durian unggul, pembibitan, sambung mini, seleksi

\section{Mini-Grafting Technology to Obtain Superior Seedling for The Community of Durian Planter in Batu Busuk}

\begin{abstract}
Batu Busuk village, Lambung Bukit, Pauh Sub-district, Padang City is one of the durians producing centre that is known for its good fruit quality. As a smallholding's plantation, durian is subsistence cultivation with minimum preservation. Generally, the durian plant derived from seed multiplication, hence the quality of the product is not uniform and less productive. It is, therefore, necessary to transfer the appropriate technology that can provide seedlings in a short time and fast, simple implementation with a high success rate. Mini-grafting technology becomes a solution for the rejuvenation of durian in Batu Busuk. The community activities start in 2018 and persist in 2020. Durian nursery has carried out from July 2019 , and the distribution of seedlings to the community has conducted in February 2020. The methods of transfer technology were counselling, plot demonstration and training to the durian planter community. Based on results, the problem in providing seedlings for rejuvenation of durian plants in Batu Busuk can be overcome by supplying seedlings from mini-grafting implementation.
\end{abstract}


Website. http://hilirisasi.lppm.unand.ac.id e-ISSN: 2621-7198

The nursery of durian with mini-grafting technology was successfully carried out and gained approximately 1100 seedlings. The mini-grafting success rate performed by durian planters reached $43 \%$, indicating that skills play a fundamental role in the success rate of grafting on durian. Evaluation of the root stock growth demonstrated that we could use medium- and large-sized seeds from any variety of durian as rootstock due to its better growth performance. Hence, the mini-grafting technology on durian nursery activity must be maintained independently and sustainably by using the scion derived from its superior local durian in order to the advancement of durian of Batu Busuk.

Keywords: Batu Busuk village, mini-grafting, nursery, selection, superior durian

\section{PENDAHULUAN}

Durian (Durio zibethinus L.) yang dikenal sebagai "King of fruits" menjadi salah satu primadona buah-buahan wilayah tropis. Buah durian bernilai ekonomi tinggi terutama di wilayah Asia Tenggara karena sangat disukai dan merupakan buah termahal diantara jenis buah-buahan tropis lainnya. Selain fisiknya yang khas (berduri) ciri khas lainnya adalah mengeluarkan bau yang menyengat (sulfuric smell) karena daging buahnya yang mengandung senyawa sulfur. Aril atau daging buah mengandung karbohidrat, fosfor dan asam askorbat yang tinggi (Ashari, 2017).

Indonesia merupakan pusat asal dan penyebaran tanaman durian di dunia (Subhadrabandhu et al., 1991; Heenkenda dan Dassanayaka, 2002; Santoso et al., 2016). Sebagai pusat asal dan penyebaran tanaman durian, Indonesia memiliki keragaman genetik tanaman durian yang besar. Berdasarkan luas panen dan produksi, Sumatera Barat menjadi salah satu sentra produksi durian di Indonesia (BPS, 2019; Kementan RI, 2019). Salah satu sentra produksi buah durian di Sumatera Barat adalah kampung Batu Busuk yang terletak di Kelurahan Lambung Bukit Kecamatan Pauh, kota Padang. Buah durian Batu Busuk menjadi juara pada lomba buah unggul yang diadakan Balai Penelitian Tanaman Buah tahun 2019 (Harian Singgalang, 2019; Padang Ekspres, 2019), namun hingga kini tanaman durian unggul tersebut belum didaftarkan sebagai varietas unggul oleh pemerintah daerah kota Padang.

Lahan durian yang dimiliki oleh masyarakat Batu Busuk umumnya berada di kawasan hutan, merupakan durian alam yang dibudidayakan secara sub-sistem atau minim pemeliharaan. Tanaman durian sudah berusia tua karena merupakan warisan keluarga yang ditanam puluhan bahkan ratusan tahun lalu (Hamid et al., 2018), sehingga produktivitas tanaman menjadi rendah. Kondisi ini sama dengan kondisi pertanaman durian di Indonesia pada umumnya. Tanaman durian yang ditemui di Batu Busuk umumnya merupakan durian hasil perbanyakan generatif yaitu menggunakan biji. Perbanyakan konvensional menggunakan biji ini menyebabkan tanaman yang dihasilkan memiliki sifat yang berbeda dengan induknya, serta waktu berbunga dan berbuah yang lebih lama sehingga kualitas buah baru bisa diketahui setelah tanaman berbuah. Pohon durian yang berasal biji akan berbuah 6-8 tahun sejak biji disemai (Ashari, 2017), bahkan berbuah lebih dari 8 tahun (Redaksi Trubus, 2005).

Tanaman yang diperbanyak secara vegetatif melalui teknik sambung (okulasi dan grafting), penyusunan atau cangkok, akan berbunga dan berbuah lebih cepat yaitu sekitar 3-5 tahun (Redaksi Trubus, 2005; Ashari, 2017). Perbanyakan dengan teknik cangkok dan susunan memiliki keterbatasan sedangkan teknik setek memiliki tingkat 
keberhasilan yang rendah pada durian (Prastowo et al., 2006; Sobir dan Napitupulu, 2015). Teknik sambung merupakan teknik yang umum dilakukan untuk perbanyakan/propagasi durian pada perkebunan durian yang diusahakan secara komersial (Wiryanta, 2010; Sobir dan Napitupulu, 2015). Perbanyakan dengan teknik sambung menghasilkan tanaman yang berbuah lebih cepat dengan kualitas produksi yang sama dengan tanaman induknya. Selain itu, karena menggunakan batang bawah yang berasal dari biji, maka teknologi perbanyakan vegetatif ini memiliki sistem perakaran yang kuat.

Sambung mini atau sambung dini pada dasarnya merupakan teknik sambung pucuk (top grafting) namun menggunakan batang bawah berumur $5-6$ minggu. Umur bibit batang bawah 5-6 minggu ini masih muda artinya bibit dapat diperoleh dalam waktu lebih dini atau lebih singkat. Berbeda dengan teknik sambung mata tunas (okulasi) atau sambung pucuk yang biasa dilakukan, ukuran bibit sambung mini lebih kecil (mini). Teknologi sambung mini merupakan inovasi teknologi dalam menghasilkan bibit seawal mungkin dengan tingkat keberhasilan yang tinggi (mencapai hingga 95\%). Teknis pengerjaan juga lebih mudah dibandingkan dengan sambung mata tunas (okulasi).

Terkait dengan permasalahan pertanaman durian di Batu Busuk yaitu kondisi tanaman durian yang membutuhkan peremajaan dan berasal dari perbanyakan generatif (Dewi-Hayati et al, 2019), maka perlu dilakukan implementasi teknologi yang dapat mengatasi permasalahan tersebut. Teknologi dimaksud adalah teknologi tepat guna yang bisa dimengerti cara kerjanya, mudah dilaksanakan dan dapat dikerjakan secara mandiri dan berkelanjutan oleh kelompok sasaran masyarakat pekebun durian di Batu Busuk. Implementasi teknologi sambung mini dapat menyediakan bibit dalam waktu singkat dan cepat serta dengan tingkat keberhasilan yang tinggi.

Tulisan pada artikel ini akan memaparkan teknologi sambung mini durian sebagai inovasi teknologi yang didiseminasikan kepada kelompok sasaran masyarakat pekebun durian Batu Busuk dan melaporkan bagaimana pelaksanaan teknik sambung mini yang dipraktekkan oleh kelompok sasaran. Melalui transfer teknologi sambung mini diharapkan masyarakat memiliki pengetahuan dan keterampilan untuk dapat melakukan peremajaan durian dan mengembangkan tanaman durian unggul yang dimilikinya secara mandiri.

\section{METODE}

Kegiatan pendampingan pekebun durian telah dimulai dari tahun 2018 dan berlanjut hingga sekarang. Kegiatan pembibitan durian dimulai dari bulan Juli 2019 dan kegiatan pemeliharaannya berlangsung hingga tahun 2020. Bibit yang dihasilkan oleh kegiatan pembibitan diserahkan/dibagikan kepada masyarakat pada bulan Februari 2020. Transfer teknologi sambung dini dilakukan tahun 2019 melibatkan sekitar 40 orang mitra sasaran yaitu masyarakat petani/pekebun durian di Batu Busuk, kelurahan Lambung Bukit, kecamatan Pauh, kota Padang.

Metode pengabdian menggunakan metode kegiatan pembelajaran masyarakat meliputi: 
(1) Penyuluhan

Penyuluhan dilakukan untuk memberikan pemahaman kepada masyarakat tentang pentingnya rehabilitasi tanaman durian yang sudah tua sehingga tidak/kurang produktif, pentingnya penggunaan varietas unggul pada komoditas tanaman tahunan dan kelebihan dari teknik perbanyakan sambung mini pada durian.

(2) Demplot

Demplot pembibitan durian penting diadakan agar kelompok sasaran bisa langsung mengamati dan membuktikan bagaimana pelaksanaan, pemeliharaan dan hasil bibit sambung mini durian.

(3) Pelatihan

Pelatihan merupakan kegiatan yang dirancang secara sistematis dan terencana untuk mengenalkan secara langsung teknologi sambung mini sekaligus mengembangkan keterampilan masyarakat dalam melakukan sambung mini.

Pelaksanaan demonstrasi dan pelatihan teknik sambung mini dibantu oleh tenaga ahli dari Balai Penelitian Tanaman Buah (Balitbu) Tropika Solok, kemudian masyarakat melakukan penyambungan didampingi oleh tim pelaksana dan mahasiswa pendamping. Mahasiswa pendamping adalah mahasiswa Fakultas Pertanian Universitas Andalas yang berpengalaman melakukan penyambungan selama kegiatan magang mereka di unit UPBS Balitbu Solok.

Pelaksanaan kegiatan transfer teknologi sambung mini meliputi kegiatan pembibitan durian dan pembagian durian hasil pembibitan.

(1) Kegiatan pembibitan meliputi kegiatan persiapan batang bawah dan batang atas (entres), penyambungan dan evaluasi hasil sambungan. Benih untuk persiapan batang bawah berasal dari durian lokal yang dipisahkan berdasarkan bobotnya yaitu besar, sedang dan kecil. Entres berasal dari varietas unggul yang diambil dari Balitbu. Hasil penyambungan dievaluasi setelah bibit sambungan berumur 3-4 minggu setelah sambung yaitu pada saat melepaskan plastik pembungkus bibit sambungan. Hasil sambungan yang berhasil selanjutnya dihitung dan dibandingkan dengan total jumlah sambungan yang dibuat untuk mendapatkan tingkat keberhasilan sambungan.

(2) Kegiatan pembagian bibit dilakukan berupa kegiatan serah terima bibit dari pelaksana kegiatan kepada ketua kelompok tani sekaligus ketua RW, diikuti dengan pembagian bibit kepada pekebun durian yang menjadi peserta kegiatan yang berpartisipasi aktif selama kegiatan berlangsung.

\section{HASIL DAN PEMBAHASAN}

Pembibitan dilakukan oleh masyarakat secara mandiri pada satu area dengan pendampingan dari tim pelaksana. Penyediaan bibit batang bawah yang berasal dari biji (benih) menjadi penting karena hingga saat ini tidak ada satupun varietas durian yang 
direkomendasikan sebagai batang bawah. Dengan demikian benih yang berasal dari apapun varietas dengan penampilan tanaman yang sehat, kondisi benih baik; tidak luka dan cacat, memberikan pertumbuhan yang seragam, serta mampu memberikan sistem perakaran yang baik, menjadi kriteria benih yang akan digunakan sebagai bibit untuk batang bawah.

Benih yang akan digunakan sebagai batang bawah dipisahkan atas tiga kategori yaitu benih besar, sedang dan kecil. Pemisahan ini dilakukan berdasarkan anggapan masyarakat untuk menunjukkan karakteristik benih yang baik untuk digunakan sebagai batang bawah. Ketiga jenis benih ditimbang dan diukur diameternya sebelum benih ditanam dalam polibag berukuran $12 \times 17 \mathrm{~cm}$ yang sudah diisi media pembibitan.

Media pembibitan adalah tanah lapisan atas $(0-20 \mathrm{~cm}$ dari permukaan tanah) yang dicampur dengan sekam padi dengan perbandingan tanah $:$ sekam $=10: 1$. Tidak dilakukan penambahan bahan organik pada media pembibitan seperti pupuk kandang karena benih masih menggunakan cadangan makanan yang ada di dalam benih untuk perkecambahan di samping menghindari serangan patogen yang mungkin terbawa oleh pupuk kandang. Benih kemudian ditanam dengan posisi horizontal dan ditutup dengan lapisan tanah hingga benih tidak terlihat dari permukaan tanah. Pada umur 6 minggu, dilakukan pengukuran tinggi dan diameter bibit, serta jumlah daun.

Pertumbuhan bibit yang dihasilkan dari pengelompokan benih ditampilkan pada Tabel 1. Kategori benih yang digunakan menghasilkan bobot dan diameter benih yang berbeda satu sama lain. Tinggi bibit dari benih yang memiliki bobot dan diameter benih yang kecil (kurang dari $15 \mathrm{~g}$ ), lebih tinggi dibandingkan benih berukuran sedang $(15-20 \mathrm{~g})$ dan benih berukuran besar (lebih dari $20 \mathrm{~g}$ ). Bibit yang berpenampilan kurus dan terlampau tinggi tidak diinginkan karena bibit menjadi lemah. Bibit ini juga memiliki diameter yang kecil sehingga sulit mendapatkan kompatibilitas dengan diameter entres. Benih yang kecil juga menghasilkan jumlah daun yang sedikit, sangat berbeda dengan jumlah daun dari benih berukuran sedang dan besar. Menurut Sudjito (2009) batang yang berukuran besar memiliki pertumbuhan yang baik sehingga bisa menyediakan dan mentransfer hara yang dibutuhkan untuk pertumbuhan tanaman. Pertumbuhan batang bawah yang baik mempercepat pertautan sambungan, sejalan dengan yang dilaporkan oleh Susanto (2003). Bibit batang bawah yang baik juga sangat penting untuk pertumbuhan tanaman hasil sambung di lapangan (Rusmin et al, 2006).

Tabel 1. Kategori Benih dan Karakteristiknya, serta Pertumbuhan Bibit Pada Umur 6 Minggu Setelah Tanam

\begin{tabular}{lccccc}
\hline $\begin{array}{l}\text { Kategori } \\
\text { benih }\end{array}$ & $\begin{array}{c}\text { Bobot benih } \\
(\mathrm{g})\end{array}$ & $\begin{array}{c}\text { Diameter } \\
\text { benih }(\mathrm{mm})\end{array}$ & $\begin{array}{c}\text { Tinggi bibit } \\
(\mathrm{cm})\end{array}$ & $\begin{array}{c}\text { Diameter bibit } \\
(\mathrm{mm})\end{array}$ & Jumlah daun $^{\#}$ \\
\hline Besar & $29.7 \pm 2.5$ & $26.7 \pm 1.4$ & $15.4 \pm 4.3$ & $3.57 \pm 0.57$ & $2.90 \pm 0.85$ \\
Sedang & $16.9 \pm 1.4$ & $24.6 \pm 1.0$ & $15.5 \pm 4.1$ & $3.49 \pm 0.64$ & $3.20 \pm 0.77$ \\
Kecil & $11.3 \pm 1.7$ & $21.1 \pm 2.2$ & $15.9 \pm 5.1$ & $3.21 \pm 0.72$ & $2.30 \pm 1.17$ \\
\hline
\end{tabular}

\footnotetext{
\# termasuk daun yang masih belum membuka.

$\pm 1 \times$ standar deviasi, jumlah sampel per kategori $=20$ benih
} 
Ukuran benih yang digunakan sebagai batang bawah berkaitan dengan ketersediaan jumlah cadangan makanan dalam benih. Benih berukuran kecil memiliki cadangan makanan yang sedikit. Itulah sebabnya kenapa Heenkenda dan Dassanayaka (2002) melaporkan bahwa benih yang memiliki bobot atau diameter benih yang kecil memiliki kegagalan berkecambah yang lebih besar dibandingkan dengan benih yang berukuran lebih besar dengan bobot lebih berat. Data pengukuran yang dilakukan penting untuk menunjukkan kepada masyarakat bahwa ukuran benih sangat krusial dalam mendapatkan bibit batang bawah yang baik.

Keberhasilan penyambungan sangat ditentukan oleh keterampilan individu yang melakukan penyambungan, kondisi batang bawah dan batang atas, serta pemeliharaan tanaman setelah proses penyambungan. Berdasarkan data hasil sambungan yang berasal dari 16 orang anggota masyarakat yang diambil secara acak dari sekitar 30 orang petani yang melakukan pelatihan, maka tingkat keberhasilan penyambungan adalah 43\%, berkisar dari $10-75 \%$. Hasil ini lebih rendah dibandingkan dengan yang dilakukan oleh mahasiswa pendamping. Rata-rata tingkat keberhasilan sambung mahasiswa adalah 74\%, berkisar dari $63-88 \%$ (Tabel 2).

Tabel 2. Keberhasilan Melakukan Teknik Sambung Dini

\begin{tabular}{lccc}
\hline Kelompok masyarakat & $\begin{array}{c}\text { Jumlah sambungan } \\
\text { total }\end{array}$ & $\begin{array}{c}\text { Jumlah sambungan } \\
\text { hidup }\end{array}$ & Tingkat keberhasilan (\%) \\
\hline Pekebun durian & 171 & 74 & $43 \pm 16.97$ \\
Mahasiswa pendamping & 43 & 32 & $74 \pm 13.81$ \\
\pm 1 x S.D. & &
\end{tabular}

Walaupun tingkat keberhasilan sambungan yang dihasilkan oleh mahasiswa lebih tinggi (74\%) dibandingkan dengan masyarakat, tingkat keberhasilan sambungan tersebut bagaimanapun masih lebih rendah dibandingkan dengan keberhasilan sambungan yang biasa diperoleh di Balai Penelitian Tanaman Buah (Balitbu) Tropika Solok. Teknologi sambung mini atau dini yang diterapkan di Balitbu Solok memiliki tingkat keberhasilan mencapai 95 - $97 \%$ dibandingkan dengan teknik propagasi vegetatif lainnya (Santoso, 2019; komunikasi personal). Ini menunjukkan bahwa penyebab utama tidak tercapainya tingkat keberhasilan sambung dini sebagaimana di Balitbu Solok adalah tingkat keterampilan dari personil yang melakukan penyambungan. Keterampilan dapat diperoleh melalui pengalaman dan ditingkatkan dengan cara memperbanyak latihan atau frekuensi melakukan penyambungan secara mandiri.

Kondisi tanaman ikut menentukan keberhasilan sambungan yang dilakukan. Kondisi batang bawah terutama umur tanaman menentukan tingkat keberhasilan sambungan. Umur tanaman batang bawah dalam kegiatan ini seragam, yaitu berumur 6- 7 minggu, namun idealnya batang bawah yang digunakan berumur $5-6$ minggu atau ketika daun belum membuka atau baru membuka 1 lembar. Semakin muda umur tanaman durian maka diduga pertautan sel-sel kambium antara batang atas dengan batang bawah akan lebih cepat. Ini terjadi karena sel-sel yang masih muda bersifat 
meristematis atau aktif membelah.

Kondisi batang atas yang digunakan sebagai entres juga ikut menentukan tingkat keberhasilan sambungan. Entres yang baik tentu saja adalah entres yang baru saja diambil dari pohon induk karena memiliki tingkat kelembaban dan kesegaran yang tinggi. Entres didatangkan dari Balitbu Tropika Solok yang terdiri atas empat varietas durian unggul yaitu Bintana, Kalumpang, Kani dan Matahari. Entres disiapkan sehari sebelumnya, kemudian untuk mempertahankan masa hidup entres dari saat pengambilan hingga keesokan harinya, dilakukan dengan cara melembabkan entres dalam kertas koran basah.

Persyaratan entres yang digunakan adalah: (1) berasal dari tanaman durian varietas unggul yang sudah pernah berbuah, (2) setek pucuk yang digunakan berasal dahan yang tumbuh ke samping, (3) daun setek pucuk berada dalam kondisi sudah tua atau setengah tua, (4) tunas berada dalam keadaan dorman, dan (5) panjang setek sekitar 1 jengkal atau berukuran panjang sekitar $20 \mathrm{~cm}$. Penyambungan dilakukan pada bagian epikotil, dengan posisi sekitar $2 \mathrm{~cm}$ di atas hipokotil. Teknik sayatan berbentuk $\mathrm{V}$ digunakan pada batang bawah sedangkan pada batang atas digunakan sayatan pada kedua sisi dengan bagian ujung berbentuk baji. Tahapan penyambungan yang dilakukan dapat dilihat pada Gambar 1 berikut ini.

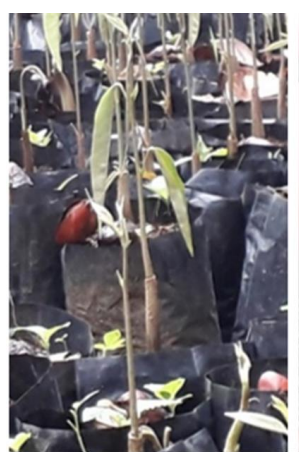

(a)

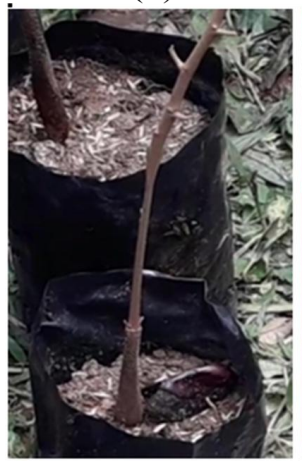

(f)

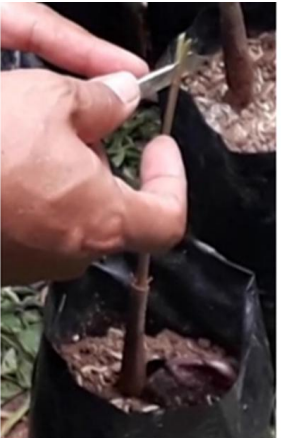

(b)

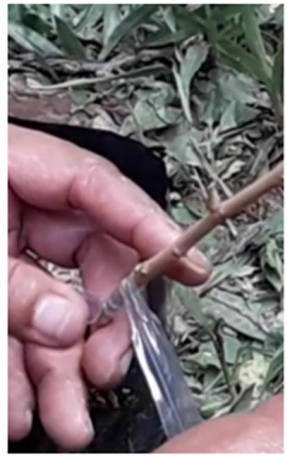

$(\mathrm{g})$

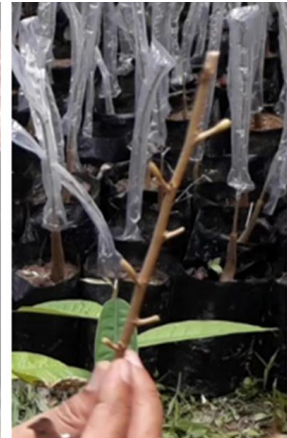

(c)

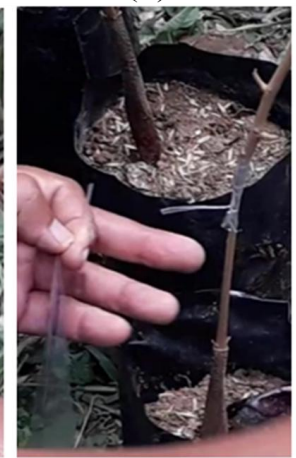

(h)

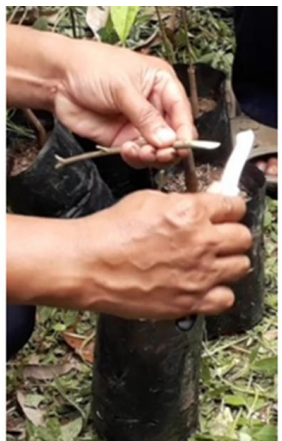

(d)

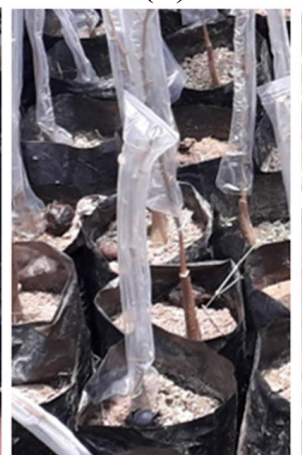

(i)

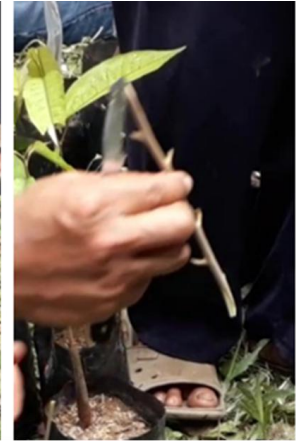

(e)

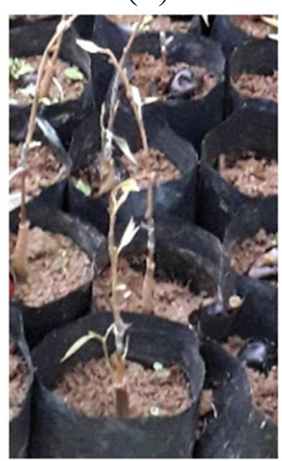

(j)

Gambar 1. Tahapan Teknik Sambung Mini Pada Durian

Tahapan penyambungan dimulai dari tahapan menyediakan bibit yang akan digunakan sebagai batang bawah (a). Bibit berumur 5 - 6 minggu, baru memiliki 1 helai daun yang sudah membuka. Bibit dipotong batangnya secara horizontal pada bagian 
epikotil, kemudian dibelah dua (b). Semakin tua bibit, maka potongan dilakukan pada posisi epikotil yang lebih tinggi. Entres diambil dari varietas unggul yang sudah pernah berbuah. Entres berasal dari cabang yang sudah setengah tua (hijau kecoklatan), namun daun sudah dalam kondisi tua (c). Ujung cabang selanjutnya diruncingkan pada kedua sisi (d-e). Entres disisipkan pada potongan horizontal tersebut (f) kemudian diikat dengan pita plastik yang sudah diregangkan dari bagian bawah ke atas (g-h). Harus dipastikan plastik menutupi bagian sambungan agar air hujan tidak tertahan pada bagian tersebut. Plastik es selanjutnya ditarik agar berukuran lebih panjang dan digunakan sebagai penutup sambungan dari atas hingga ke batang bawah (i). Plastik penutup baru bisa dilepas dari bibit ketika hasil sambungan sudah memunculkan tunastunas baru yaitu pada saat bibit berumur 3-4 minggu (j).

Kegiatan transfer atau implementasi teknologi sambung pada berbagai komoditas tanaman telah dilaporkan keberhasilannya pada tanaman kesemek (DewiHayati et al., 2018a) dan alpukat (Dewi-Hayati et al., 2018b). Permasalahan utama berkaitan dengan tingkat keberhasilan teknik sambung adalah keterampilan di samping faktor pemeliharaan tanaman selama di pembibitan.

Pelaksanaan sambung mini yang dilakukan dan hasil bibit yang diperoleh dapat dilihat pada Gambar 2. Total terdapat kurang lebih 1100 bibit yang berhasil disambung pada kegiatan pelatihan penyambungan durian. Bibit dipelihara secara mandiri oleh pekebun durian di pembibitan durian Batu Busuk. Selanjutnya bibit umur 5 bulan diserahterimakan kepada masyarakat melalui ketua RW III sekaligus ketua kelompok tani Patamuan Jaya (Gambar 3), untuk selanjutnya dibagi kepada masyarakat pekebun durian. Bibit ini dipelihara oleh masing-masing hingga bibit dapat mencapai tinggi minimal $75 \mathrm{~cm}$ sebelum di pindah tanam ke lapangan.

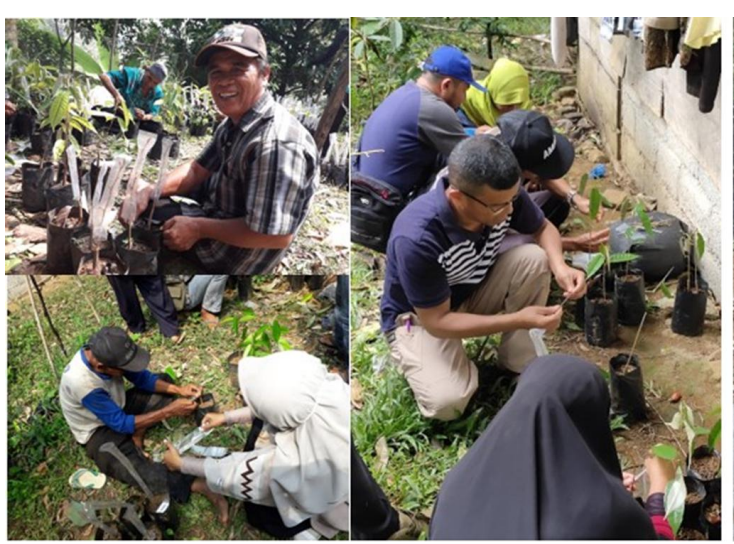

(a)

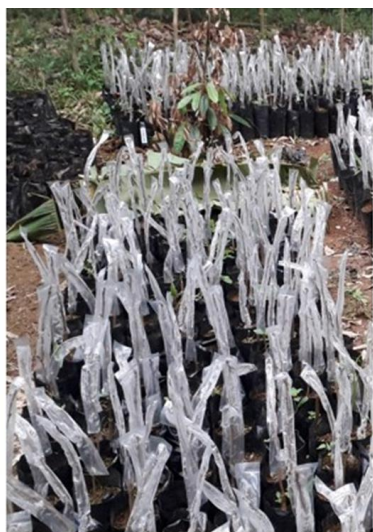

(b)

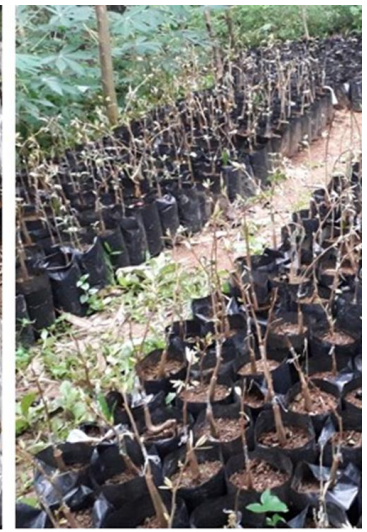

(c)

Gambar 2. Kegiatan Penyambungan Durian Yang Dilakukan Masyarakat, (a) Antusiasme Masyarakat Melakukan Penyambungan, (b) Hasil Sambung Mini, (c) Bibit Sambung Mini Yang Berhasil 

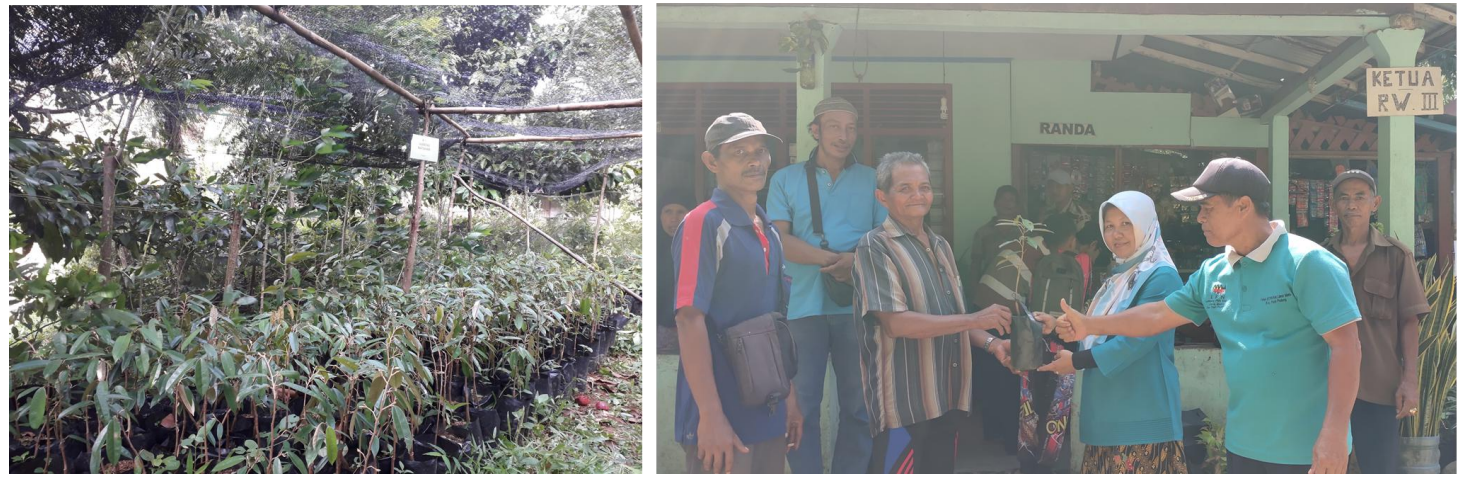

Gambar 3. Serah Terima Bibit Durian di Pembibitan Dari Pelaksana Kepada Masyarakat

\section{KESIMPULAN DAN SARAN}

Berdasarkan kegiatan yang telah dilakukan, dapat disimpulkan permasalahan penyediaan bibit untuk peremajaan tanaman durian di Batu Busuk dapat diatasi dengan penyediaan bibit durian sambung mini. Transfer teknologi sambung mini berhasil dilakukan dengan mendapatkan kurang lebih 1100 bibit yang dipelihara di pembibitan. Tingkat keberhasilan sambung mini yang diterapkan oleh pekebun durian baru mencapai $43 \%$, mengindikasikan keterampilan berperan penting terhadap tingkat keberhasilan sambung. Evaluasi terhadap pertumbuhan bibit menunjukkan bahwa benih berukuran sedang dan besar sebaiknya digunakan sebagai sumber bibit untuk batang bawah karena memberikan pertumbuhan yang lebih baik dibandingkan benih berukuran kecil.

Bibit yang dihasilkan dari kegiatan pembibitan durian masih belum mencukupi sehingga disarankan agar kegiatan pembibitan durian dapat terus dilakukan secara mandiri dan berkelanjutan dengan menggunakan entres dari durian unggul Batu Busuk sendiri. Dengan demikian kegiatan pembibitan durian unggul Batu Busuk menjadi upaya nyata untuk peremajaan durian dan sekaligus pengembangan durian unggul Batu Busuk. Dukungan pemerintah daerah diperlukan dalam upaya pendaftaran varietas lokal durian Batu Busuk sekaligus mendukung Batu Busuk sebagai destinasi agro wisata.

\section{UCAPAN TERIMA KASIH}

Penulis mengucapkan terima kasih kepada LPPM Universitas Andalas atas skim Iptek bagi Dosen dan Masyarakat (IbDM) tahun 2019 dan PKM Dikti tahun 2020 yang diterima oleh penulis. Ucapan terima kasih juga disampaikan kepada bapak Sukarmin dari Balitbu Tropika Solok, Lurah Lambung Bukit, Bapak Idris, Bapak Anwar dan masyarakat Batu Busuk, Kecamatan Pauh Kota Padang serta mahasiswa Fakultas Pertanian Universitas Andalas yang berpartisipasi dalam kegiatan ini. 


\section{DAFTAR PUSTAKA}

Ashari, S. 2017. Durian: King of the Fruits. UB Press, Malang, Indonesia. 264 hal.

Badan Pusat Statistik [BPS]. 2019. Produksi Tanaman Buah-Buahan https://www.bps.go.id/. [diakses tanggal 16 November 2019].

Dewi-Hayati, P.K., S. Efendi dan R. Irawan. 2018b. Diseminasi teknologi sambung pucuk pada alpukat giri maju di Kabupaten Pasaman Barat. Jurnal Ilmiah Pengabdian kepada Masyarakat Logista, 2(2): 25-31.

Dewi-Hayati, P.K., Sutoyo, Netti Herawati, Nini Marta dan Kuswandi. 2018a. Transfer teknologi sambung menggunakan anakan (root-sucker) sebagai batang bawah untuk propagasi tanaman kesemek di Batu Bagiriek Alahan Panjang. Jurnal Hilirisasi IPTEKS, 1(3):11-17

Dewi-Hayati, P.K., Sutoyo, H. Hamid, Juniarti dan S. Febjislami. 2019. PKM Batu Busuk melalui teknologi propagasi masal pada durian dan introduksi durian varietas unggul. Laporan akhir IBDM. Universitas Andalas [tidak dipublikasikan]

Hamid, H., P.K. Dewi-Hayati, S. Sutoyo, E. Swasti, A. Zainal, T.B. Prasetyo, P.J. Santoso. 2018. Pengembangan Durian Batu Busuk, Kelurahan Lambung Bukit, Kota Padang. Jurnal Ilmiah Pengabdian kepada Masyarakat Logista, 2(2):4451 .

Harian Singgalang. 2019. Durian Batu Busuk Juarai Lomba Balitbu, Ini Keunggulannya. 17 Desember 2019 [https://hariansinggalang.co.id/durianbatu-busuk-juarai-lomba-balitbu-ini-keunggulannya/] [diakses tanggal 28 Juli 2020].

Heenkenda, H.M.S, and D.R.S. Dassanayaka. 2002. Improvement of grafting methods for propagation of durian (Durio zibethinus Murr.). Annals of the Sri Lanka Department of Agric. 4:129-136

Kementerian Pertanian Republik Indonesia [Kementan RI]. 2019. Luas Panen Durian Menurut Provinsi, Tahun 2014-2018. https://www.pertanian.go.id/. [diakses tanggal 16 November 2019].

Padang Ekspres, 2019. Durian Batu Busuk Dominasi Durian Unggul. [17 Desember 2019]. 
Prastowo, N.H., J.M. Roshetko, G.E.S. Maurung, E. Nugraha, J.M. Tukan, dan F. Harum. 2006. Teknik Pembibitan dan Perbanyakan Vegetatif Tanaman Buah. World Agroforestry Centre (ICRAF) \& Winrock International, Bogor, Indonesia. 45 hal

Redaksi Trubus. 2005. Mengebunkan Durian Unggul. Penebar Swadaya.

Rusmin, D., Sukarman, dan Melati. 2006. Pengaruh batang atas dan bawah terhadap keberhasilan penyambungan jambu mete (Anacardium occidentale L.). J. Littri 12(1):32-37

Santoso, P.J., A. Granitia, N.L.P. Indriyani dan A. Pancoro. 2016. Analisis lokus dan keragaman sumber daya genetik durian (Durio sp.) berdasarkan marka mikrosatelit. H. Hort. 26(1):9-20

Sobir dan R.M. Napitupulu. 2015. Berkebun durian unggul. Penebar Swadaya

Subhadrabandhu, S., Schneemann, J.M.P. and Verheij, E.W.M. 1991. Durio zibethinus Murray [Internet] Record from Proseabase. Verheij, E.W.M. and Coronel, R.E. (Editors). PROSEA (Plant Resources of South-East Asia) Foundation, Bogor, Indonesia. http://www.proseanet.org. [diakses tanggal 16 November 2019]

Sudjijo, 2009. Pengaruh ukuran batang bawah dan batang atas pada pertumbuhan durian Monthong, Hepe dan DCK-01. J. Hort 19(1):89-94

Susanto. S. 2003. Pertumbuhan dan pembuahan jeruk besar Cikoneng pada beberapa jenis batang bawah. J. Ilmu Pertanian. 10(1):57-63.

Wiryanta, B.T.W. 2010. Panen durian di pekarangan rumah. Agro Media 